\title{
Detailed surface co-seismic displacement of the 1999 Chi-Chi earthquake in western Taiwan and implication of fault geometry in the shallow subsurface
}

\author{
Chung Huang ${ }^{\mathrm{a}, \mathrm{b}}$, Yu-Chang Chan ${ }^{\mathrm{b}, *}$, Jyr-Ching $\mathrm{Hu}^{\mathrm{a}}$, Jacques Angelier ${ }^{\mathrm{c}}$, Jian-Cheng Lee ${ }^{\mathrm{b}}$ \\ a Department of Geosciences, National Taiwan University, Taipei, Taiwan \\ ${ }^{\mathrm{b}}$ Institute of Earth Sciences, Academia Sinica, Taipei, Taiwan \\ ${ }^{c}$ Observatoire Océanologique de Villefranche (UPMC) and Géosciences Azur, Villefranche-sur-Mer, France
}

\section{A R T I C L E I N F O}

\section{Article history:}

Received 8 November 2007

Received in revised form 30 May 2008

Accepted 1 June 2008

Available online 7 June 2008

\section{Keywords:}

Earthquake fault

Co-seismic displacement

Fault geometry

\begin{abstract}
A B S T R A C T
The northern segment of the Chelungpu Fault shows an unusually large co-seismic displacement from the event of the Mw 7.6 Chi-Chi earthquake in western Taiwan. Part of the northern segment near the Fengyuan City provides an excellent opportunity for characterizing active thrust-related structures due to a dense geodetic-benchmark network. We reproduced co-seismic deformation patterns of a small segment of this Chelungpu Fault using 924 geodetic benchmarks. According to the estimated displacement vectors, we identified secondary deformations, such as local rigid-block rotation and significant shortening within the hanging wall. The data set also allows us to determine accurately a 3D model of the thrust fault geometry in the shallow subsurface by assuming simple relations between the fault slip, and the horizontal and vertical displacements at the surface. The predicted thrust geometry is in good agreement with borehole data derived from two drilling sites close to the study area. The successful prediction supports our assumptions of rigid displacement and control of displacement in the hanging wall by the fault geometry being useful first approximations.
\end{abstract}

(c) 2008 Elsevier Ltd. All rights reserved.

\section{Introduction}

Large earthquakes generated by thrust activation commonly induce complex deformation near the surface, especially in the hanging wall as happened in the 1980, with the Mw 7.3, El Asnam earthquake (Philip and Meghraoui, 1983). Likewise, the 1999, Mw 7.6, Chi-Chi earthquake in west Central Taiwan was one of the largest onshore earthquakes in the past century (Fig. 1). This earthquake re-activated the 100 -km-long Chelungpu Fault, with a N-S striking surface rupture that closely followed the mountain front of the Taiwan mountain belt (Central Geological Survey, 1999; Kao et al., 2000; Angelier et al., 2001; Lee et al., 2002; Chen et al., 2003; Chan et al., 2005; Lee and Chan, 2007).

From the geodynamic point of view, the Chi-Chi earthquake was a typical expression of the ongoing collision of the Taiwan orogen in terms of seismotectonic location and mechanism (Ho, 1986; Kao and Chen, 2000; Kao and Angelier, 2001). From the point of view of structural geology, the deformation in the hanging wall was complex, involving multiple faults (Wang et al., 2002a,b) and pop-up structures (Lee et al., 2002). In particular, partitioning

\footnotetext{
* Corresponding author. Institute of Earth Sciences, Academia Sinica, Nankang, 128 Academic Road, Section II, Taipei 115, Taiwan. Tel.: +886 2 27839910x411; fax: +886227839871 .

E-mail address: yuchang@earth.sinica.edu.tw (Y.-C. Chan).
}

accommodated the oblique thrusting between the main Chelungpu thrust and a hanging wall deformation zone with significant leftlateral strike-slip (Angelier et al., 2003a,b).

The Philippine Sea plate converges on the Chinese continental margin in a NW-SE direction across the Taiwan mountain belt at a rate of $8.2 \mathrm{~cm}$ per year (Yu et al., 1997). This convergence behavior contrasts to the longer term, WNW-ESE-directed contractional deformation of Taiwan (Yu et al., 2001; Chang et al., 2003). The contraction is consistent with the maximum compression direction indicated by stress inversion of focal mechanisms of the Chi-Chi main shock and aftershock sequence (Angelier, 2002). Both surfacedeformation and crustal-stress characteristics agree with the direction of plate convergence (e.g., Seno et al., 1993) based on numerical modelling of the relationships between relative displacement, strain and stress (Hu et al., 1996, 2001). The strain partitioning along the Chelungpu Fault can be regarded as a local expression of the accommodation of NW-SE convergence that is oblique to the NNE-SSW structural grain of the collision belt, which represents a counter-clockwise deviation of shortening direction as compared with relative plate motion.

In this paper, we conduct a detailed analysis of active deformation and related faults by using a dense network of geodetic benchmarks and two boreholes. We determine the co-seismic displacement, and construct a 3D model of deformation at depth to determine the fault geometry and behavior in the shallow subsurface. 


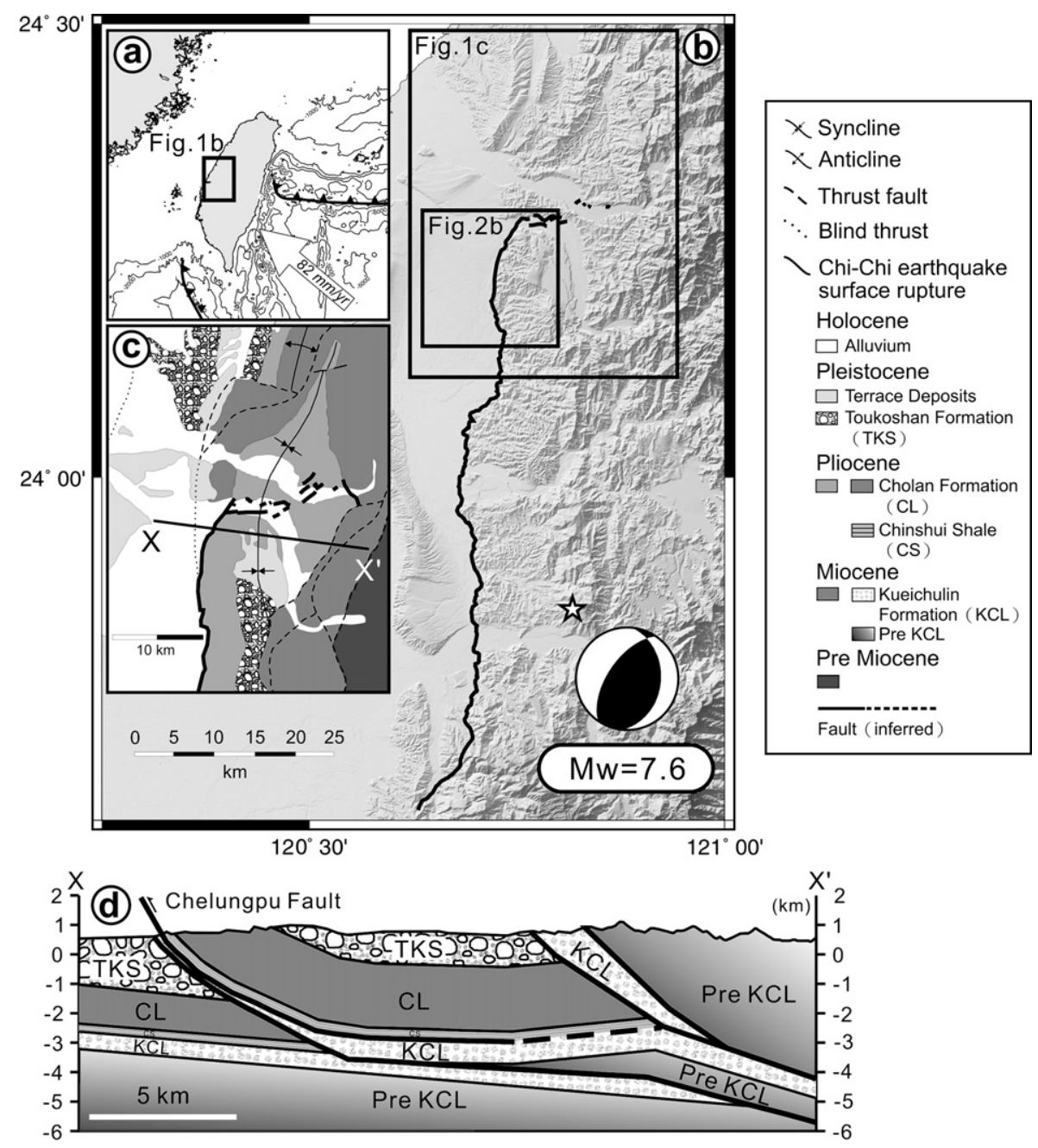

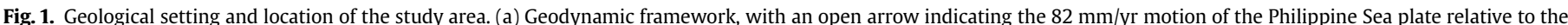

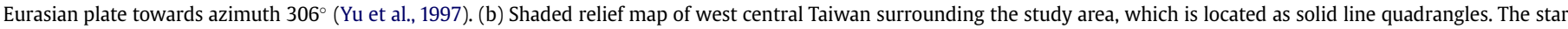

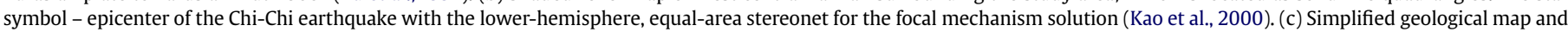
location of the cross-section $\left(X-X^{\prime}\right)$. (d) Geological cross-section $X-X^{\prime}$ modified from Mouthereau et al., 2001.

\section{The data: a dense network of city-planning benchmarks}

In Fengyuan City, the second largest town of Taichung County, accurate $1 / 1000$-scale urban-planning maps were created before the 1999 Chi-Chi earthquake. We use these maps and the geodetic measurements of benchmarks made before and after the earthquake as the basis for our analysis (Fig. 2).

In the study area, the vertical offset across the Chelungpu Fault scarp ranged from 2.5 to $4 \mathrm{~m}$, whereas the horizontal displacement was approximately $7 \mathrm{~m}$ (Central Geological Survey, 1999). Such large displacements produced complex deformation in the hanging wall, creating many fissures, faults, and small folds (Kelson et al., 2001). However, detailed characterization of deformation was limited by the lack of quantitative data. Although previous studies characterized co-seismic displacement (Kelson et al., 2001; Lin et al., 2001; Lee et al., 2002, 2003; Angelier et al., 2003a,b; Dong et al., 2003), these studies did not reveal much concerning the deformation pattern in the hanging wall. Measurements of several GPS stations in this region (Central Geological Survey, 1999; Yu et al., 2001) provided vertical and horizontal displacement data; yet, their limited spatial distribution density prevented spatially detailed deformation analysis. In contrast, the densely spaced distribution of the city-planning benchmarks in Fengyuan provides us with a novel basis to perform accurate local determination of the deformation within the hanging wall. The resolution of this approach makes it advantageous compared to other approaches such as the correlation of aerial photographs or satellite images (Dominguez et al., 2003) because of greater accuracy for vertical relative displacements.

\section{Determination of horizontal and vertical co-seismic displacements: the method}

The city map provides accurate locations of human constructions, in particular houses, roads, and benchmarks. Because of extensive surface damage and large landform modification, the eastern part of Fengyuan City was remapped after the Chi-Chi earthquake. The map before the Chi-Chi earthquake was surveyed in 1992, adopting the coordinate system of the Taiwan Datum 67 (TWD 67), which was commonly used in Taiwan in the 1970s1990s. The map made after the Chi-Chi earthquake was finished in 2002, using the coordinate system of the Taiwan Datum 97 (TWD 97), a new system adopted in Taiwan recently. Not only does the new map contain all the old city-planning benchmarks, it also includes the surface rupture of the earthquake and a Digital Terrain Model of a few meters resolution.

To compare these two maps, we first transformed the coordinates of benchmarks of the new map from TWD 97 to TWD 67. 


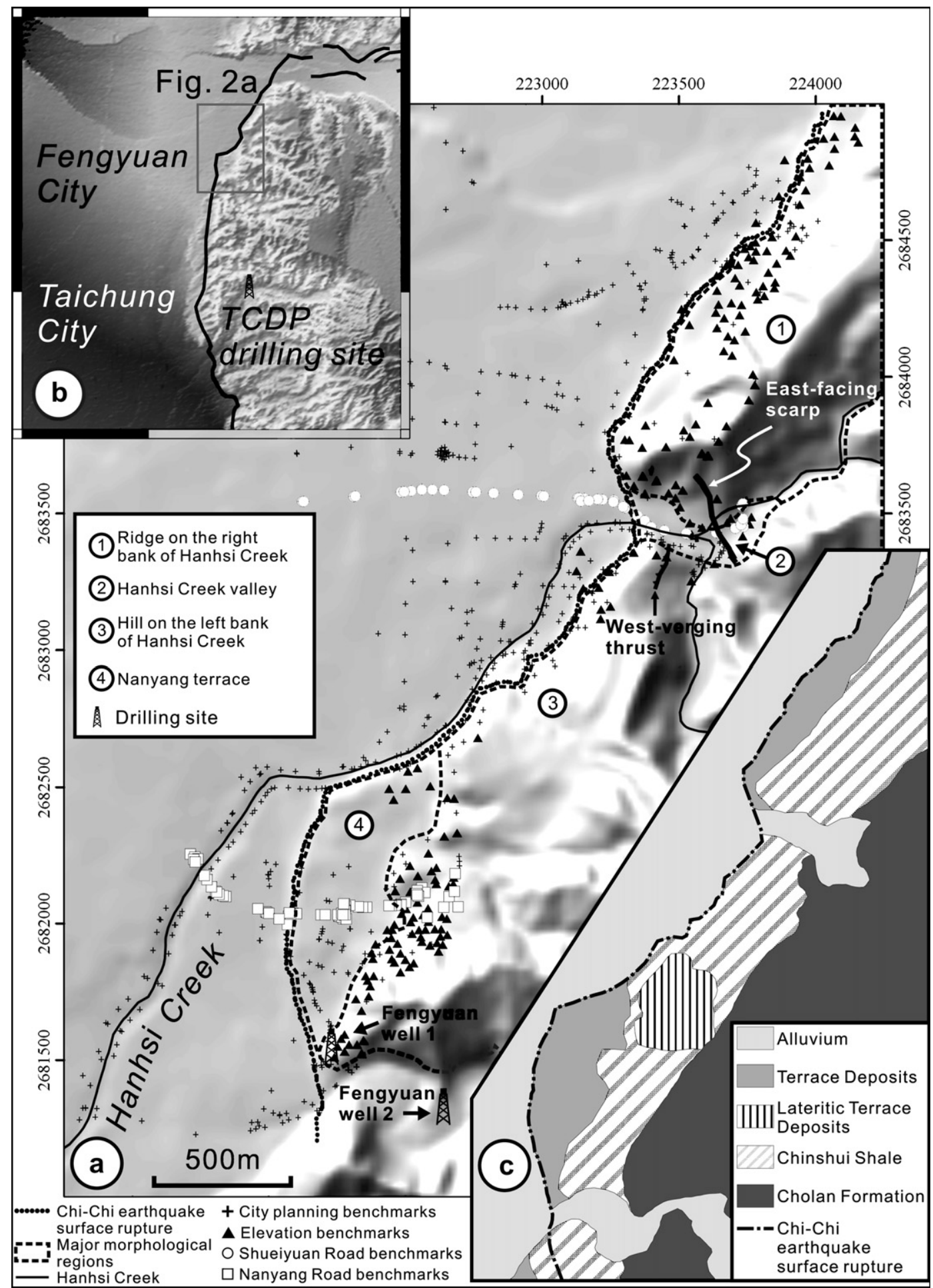

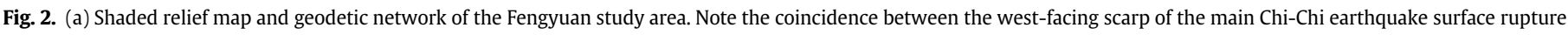

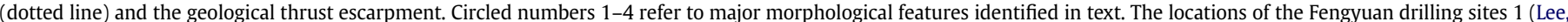

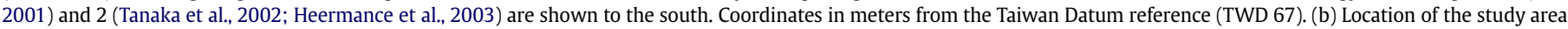
(see also Fig. 1). (c) Schematic geological map of the study area with legend.

Then, by comparing the coordinates of old and new benchmarks, we obtained the horizontal offsets of the benchmarks, which represent the horizontal co-seismic displacements in eastern Fengyuan City. The 924 benchmarks distributed in the study area include 724 position benchmarks ( 251 benchmarks in the hanging wall and 473 benchmarks in the footwall) and 200 elevation benchmarks (Fig. 2). The minimum standard of the horizontal uncertainty in benchmark coordinates was to be less than $10 \mathrm{~cm}$, according to the codes of urban-planning measurements (Ministry of the Interior, 2001). However, in practice, the actual horizontal uncertainty is much smaller at commonly less than $1-2 \mathrm{~cm}$ (Personal communication, 2006, Chung-Hsin Survey Company). Thus, 
considering that the co-seismic displacement of the hanging wall was generally greater than $5 \mathrm{~m}$, the uncertainty of benchmark locations is small.

However, the determination of the vertical offsets is complicated by protocol differences between the two surveys. First, only a few elevation benchmarks were surveyed before and after the Chi-Chi earthquake. Second, some of the old 200 elevation benchmarks, which are mostly distributed on the hanging wall side of the Chelungpu Fault, are near where a number of new elevation benchmarks were installed. We consequently selected 62 new benchmarks that are located as close as possible to old benchmarks with distance ranging from 4 to $85 \mathrm{~m}$ and averaging $28 \mathrm{~m}$. We adopted the elevation of the new benchmarks as an approximation of the new elevation for the old benchmarks, assuming that over short distance the elevation is nearly the same. This technique introduces an additional uncertainty to determining the vertical displacement. Because the resultant displacement pattern fits well with the local result of the GPS survey (Yu et al., 2001) and resembles the strong-motion seismograph data recorded by the Central Weather Bureau of Taiwan, we consider that our determination of vertical displacement for such couples of old and new benchmarks is generally reliable to within less than $10 \mathrm{~cm}$.

\section{Horizontal and vertical movement: the results}

\subsection{Horizontal component of displacement}

The displacement vectors show a common NW direction (average azimuth $329.9^{\circ} \pm 3.8^{\circ}$ ) (Fig. 3). This consistency is also illustrated in the azimuth histogram of Fig. 3, showing a narrow peak between azimuths $325^{\circ}$ and $330^{\circ}$, with almost $60 \%$ of the data. Most displacements are $7-8.5 \mathrm{~m}$, but it is worth noting that almost $50 \%$ of vectors larger than $8 \mathrm{~m}$ are located in the hanging wall at a distance to the rupture trace, reflecting partially the internal deformation of the hanging wall.

To better characterize the displacement variation within the hanging wall, we calculated horizontal displacement vectors with respect to two selected reference points located within the hanging wall. The first reference point is the benchmark \#1019 (Fig. 4a), which is located in the northern part of the study area (area 1, Fig. 2) on top of a ridge. This reference point in northern Fengyuan reveals an apparent clockwise rotation around it from the Chi-Chi earthquake with a magnitude of about $10-15 \%$ of the total displacement at each location (Figs. 3 and 4a). This relative displacement pattern favours a northern block undergoing a minor clockwise rotation during its major displacement to the NW. Both the trends and the amplitudes of the displacement vectors relative to benchmark \#1019 are consistent with a rigid rotation around a pole close to this reference point. The displacement is about $1 \mathrm{~m}$ at a distance of about $500 \mathrm{~m}$ from the center, indicating a clockwise rotation of about $7 \mathrm{~min}$.

The second reference point is the benchmark \#1291, which is located on a hill in the southern area 3 (Figs. 2 and 4 b). The average vector length on the hill near the reference point is clearly smaller than that on the terrace farther to the west. Likewise, along the length of the boundary between areas 3 and 4 (Fig. 2), vector magnitude increases about $1 \mathrm{~m}$ onto the terrace. Previous geomorphological study interpreted the terrace boundary as a possible fault (Ota et al., 2004). Our results indicate that this fault was active with a displacement of about $1 \mathrm{~m}$, as a thrust with left-lateral component of motion, during the Chi-Chi earthquake.

Although several displacement vectors along the west edge of the terrace are inconsistent with this interpretation (area 4), we found that the benchmarks in this area were old ones, not the new post-earthquake benchmarks. We infer that these inhomogeneous local displacements reflect co-seismic block sliding at the edge of

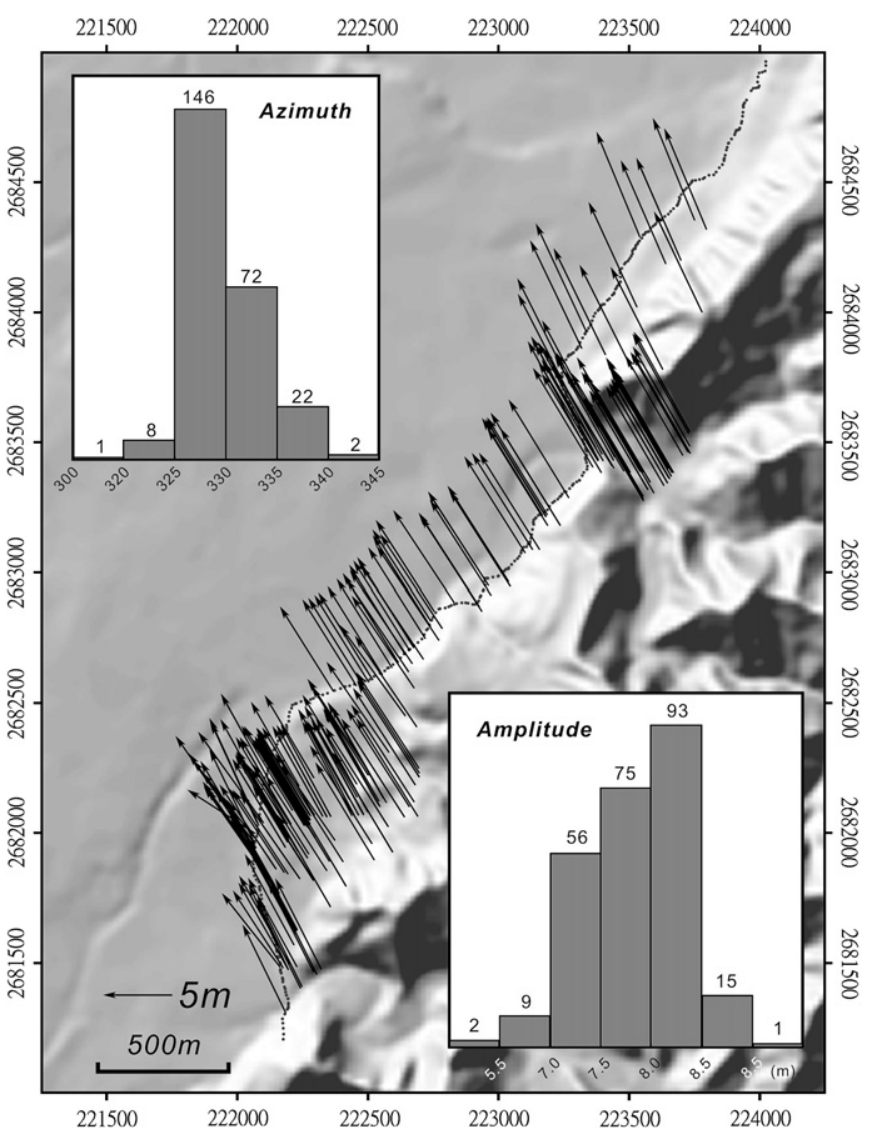

Fig. 3. Co-seismic displacements of the Chi-Chi earthquake in the hanging wall, with respect to the origin of TWD 67 System (Transverse Mercator Two-Degree Grid System). Background shaded relief map and coordinates of the TWD 67 reference frame are same as in Fig. 2. Main surface rupture is shown as line of small dots. Horizontal motion vectors from geodetic data are shown as arrows. Two histograms show the distribution of azimuths in degrees and amplitudes in meters with classes of $5^{\circ}$ for azimuths and $0.5 \mathrm{~m}$ for amplitudes, and numbers of data at column tops.

the terrace, instead of a deep-seated movement. This interpretation is also strengthened by the displacement pattern along two profiles stated in the following section.

\subsection{Displacement along profiles: Shueiyuan and Nanyang Roads}

In the northern study area, the Shueiyuan Road trends E-W and its eastern section follows the right bank of the Hanhsi Creek, east of the main thrust (benchmarks in Fig. 2), exposing to the Pliocene Chinshui Shale Formation (Chinese Petroleum Corporation, 1974). This road crosses a spectacular pop-up structure of a few meters height that formed during the Chi-Chi earthquake. A city-planning survey line was set up along this road between points located $1400 \mathrm{~m}$ west of the main surface rupture and $400 \mathrm{~m}$ east of it. The eastern end is located $125 \mathrm{~m}$ east of an east-facing scarp, which is considered to be a backthrust (Kelson et al., 2001; Dong et al., 2003).

We projected all the reconstructed displacement vectors along the Shueiyuan Road profile to show the westward and northward components of the co-seismic horizontal displacement (Fig. 5). The hanging wall is offset relative to the footwall by about $4.2 \mathrm{~m}$ westward (Fig. 5a) and $7.9 \mathrm{~m}$ northward (Fig. 5b). Whereas the westward displacement component is nearly constant in the hanging wall, the northward displacement decreases linearly in the hanging wall eastward from the rupture by several 10th's of a meter. 


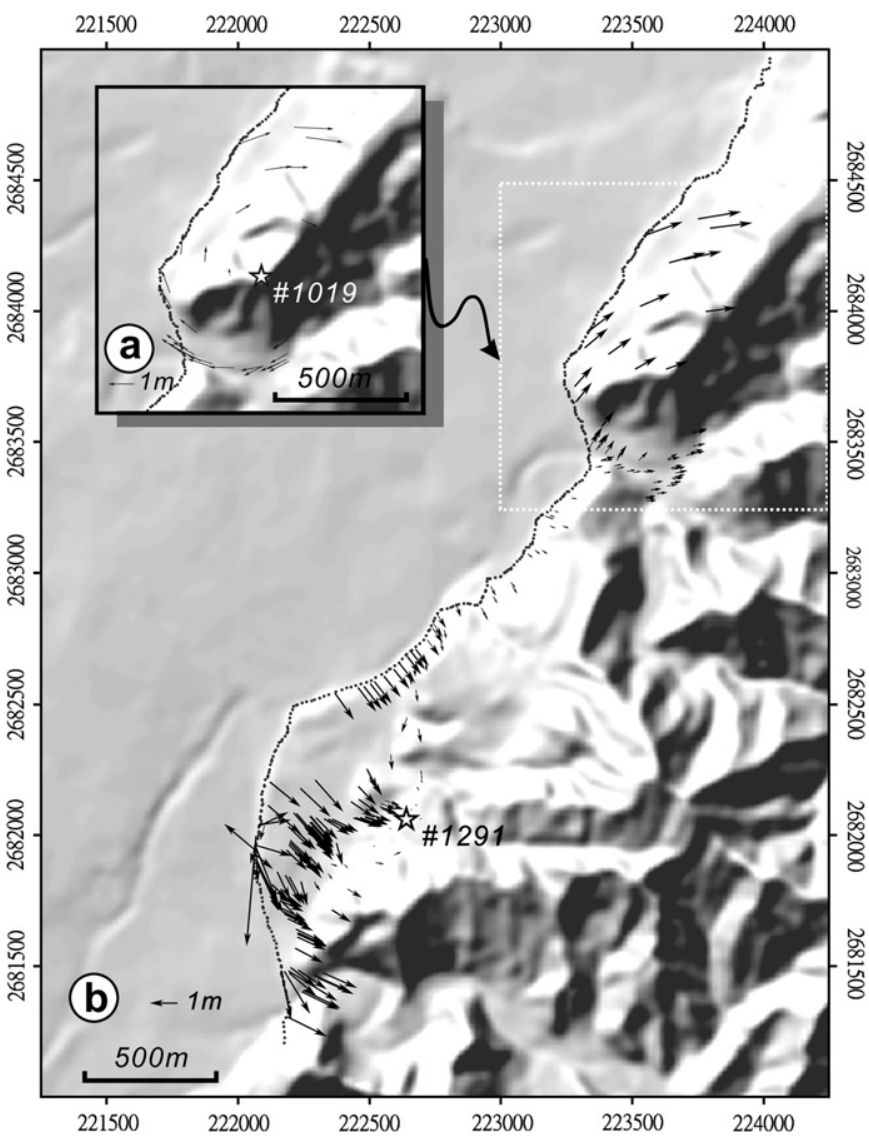

Fig. 4. Components of displacement in appropriate reference systems to characterize the deformation of the hanging wall in Fengyuan City. (a) Co-seismic displacements in the northern hanging wall area relative to the city-planning benchmark \#1019 (open star). (b) Co-seismic displacements relative to the city-planning benchmark \#1291 (open star). The line of black dots shows the main surface rupture trace. Background shaded relief map and coordinates of the TWD 67 reference frame are the same as in Fig. 2.

In the southern study area, the Nanyang Road trends approximately E-W except close to its western tip where it turns to NW (benchmarks in Fig. 2). From west to east, it crosses the north-south trending rupture trace of the Chi-Chi earthquake, then a Quaternary alluvial terrace, and a hill domain underlain by the Chinshui Shale (Fig. 2c). Considering the westward and northward components of displacement at benchmarks along the Nanyang Road profile, the data show steps in magnitude, which we interpret as minor faults (Fig. 6). The different areas are labelled 1-7 in Fig. 6.

Considering the westward component (Fig. 6a), the different steps have values of about 5-8 cm (positive, groups 1-2), 12-16 cm (negative, groups $2-3$ ), $3-5 \mathrm{~cm}$ (negative, groups $3-4$ ), $15-18 \mathrm{~cm}$ (positive, groups 4-5), 19-28 cm (positive, groups 5-6) and 44$59 \mathrm{~cm}$ (positive, groups 6-7). Positive differences in westward displacement indicate a reverse component of co-seismic faulting, whereas negative differences reveal extensional co-seismic faulting (between groups 2-3 and 3-4). These occurrences of local extension correlate well with the presence of dense fissures and tension cracks at several localities in the hanging wall (Angelier et al., 2001, 2003b; Kelson et al., 2001; Lin et al., 2001, 2003). The discontinuity in westward motion between groups 6 and 7 is a large secondary displacement difference of more than $50 \mathrm{~cm}$ across a distance of only $8 \mathrm{~m}$ between benchmarks, indicating the presence of a secondary fault with a greater deformational role in the hanging wall.

Considering northward displacement across the steps, the stepwise form of the displacement changes is not as obvious as for westward displacement (Fig. 6b vs. 6a). The changes are about
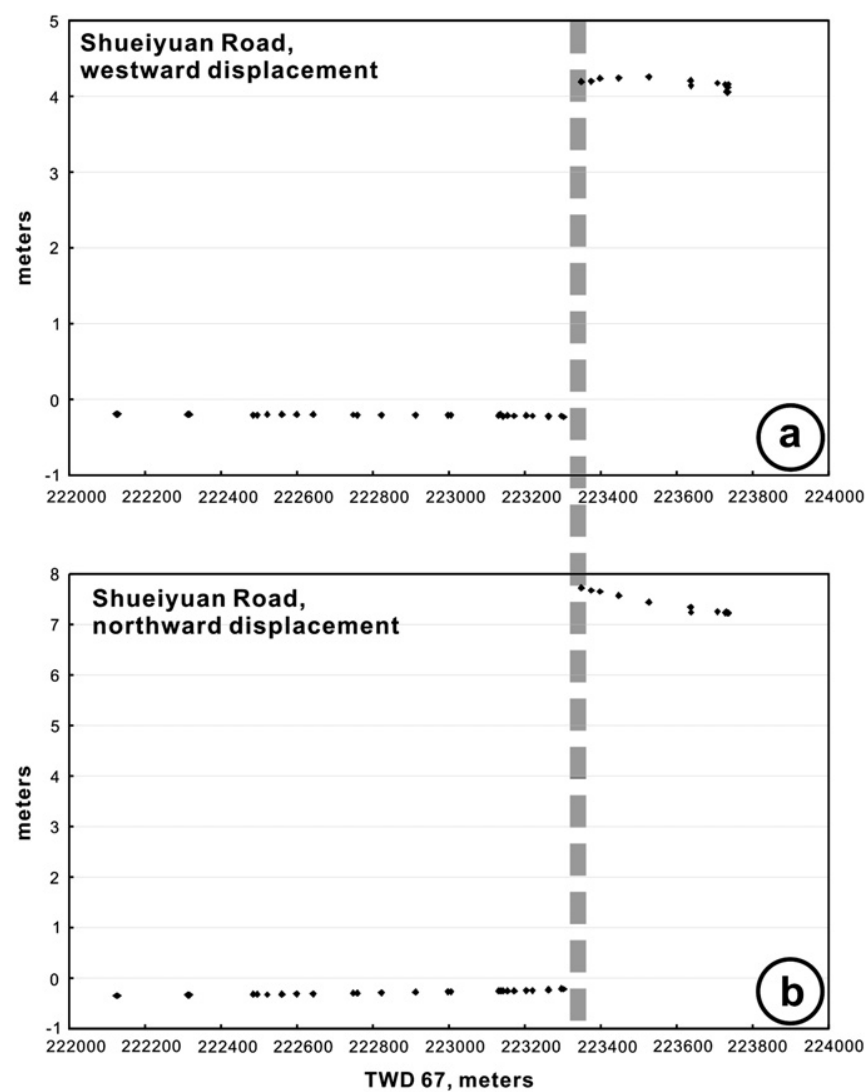

Fig. 5. Displacement data of the Shueiyuan Road profile, with horizontal distance ( $x$ axis) and horizontal displacement component ( $y$-axis) in meters. (a) Westward displacement component. (b) Northward displacement component. Location of major west-directed thrust earthquake-rupture is shown as thick grey dashed line.

$10 \mathrm{~cm}$ (negative, groups 1-2), $15 \mathrm{~cm}$ (positive, groups 2-3), a progressive increase of about $63 \mathrm{~cm}$ over a W-E distance of $239 \mathrm{~m}$ for groups 3-6, and a $23 \mathrm{~cm}$ offset (positive) between groups 6 and 7 . Note that a positive difference implies a left-lateral component of motion along $\mathrm{N}-\mathrm{S}$ trending faults, whereas a negative difference is a right-lateral component.

Combining both components of horizontal displacement along the Nanyang Road profile (Fig. 7), we infer that in the middle and eastern portions of the terrace contain three minor faults, one of them with more than $1 \mathrm{~m}$ of offset. These minor faults accommodate both reverse and left-lateral displacements, whereas the extensional sub-area detected in the middle part of the terrace represents the hinge of a small anticline, presumably a pop-up like structure (Kelson et al., 2001). The terrace edge, where scattered displacement values are present, signifies collapsed area at the tip of the thrust unit.

\subsection{Southern terrace: internal co-seismic deformation}

By comparing all 174 available benchmarks inside the whole terrace area crossed by the Nanyang Road profile, we correlated the compressional and tensional zones, respectively (Fig. 7). We delineated a consistent zone of co-seismic compression with about $1 \mathrm{~m}$ of E-W shortening that runs parallel to the boundary between hills and terrace. The other minor zones, which reveal co-seismic compression inside the terrace, trend N-S and are consistent with the geomorphic features. In this southern Fengyuan area, the Chelungpu Fault clearly includes two main branches at the western edge and near the eastern edge of the terrace, separated by a subdomain that is mainly the terrace itself where limited co-seismic 

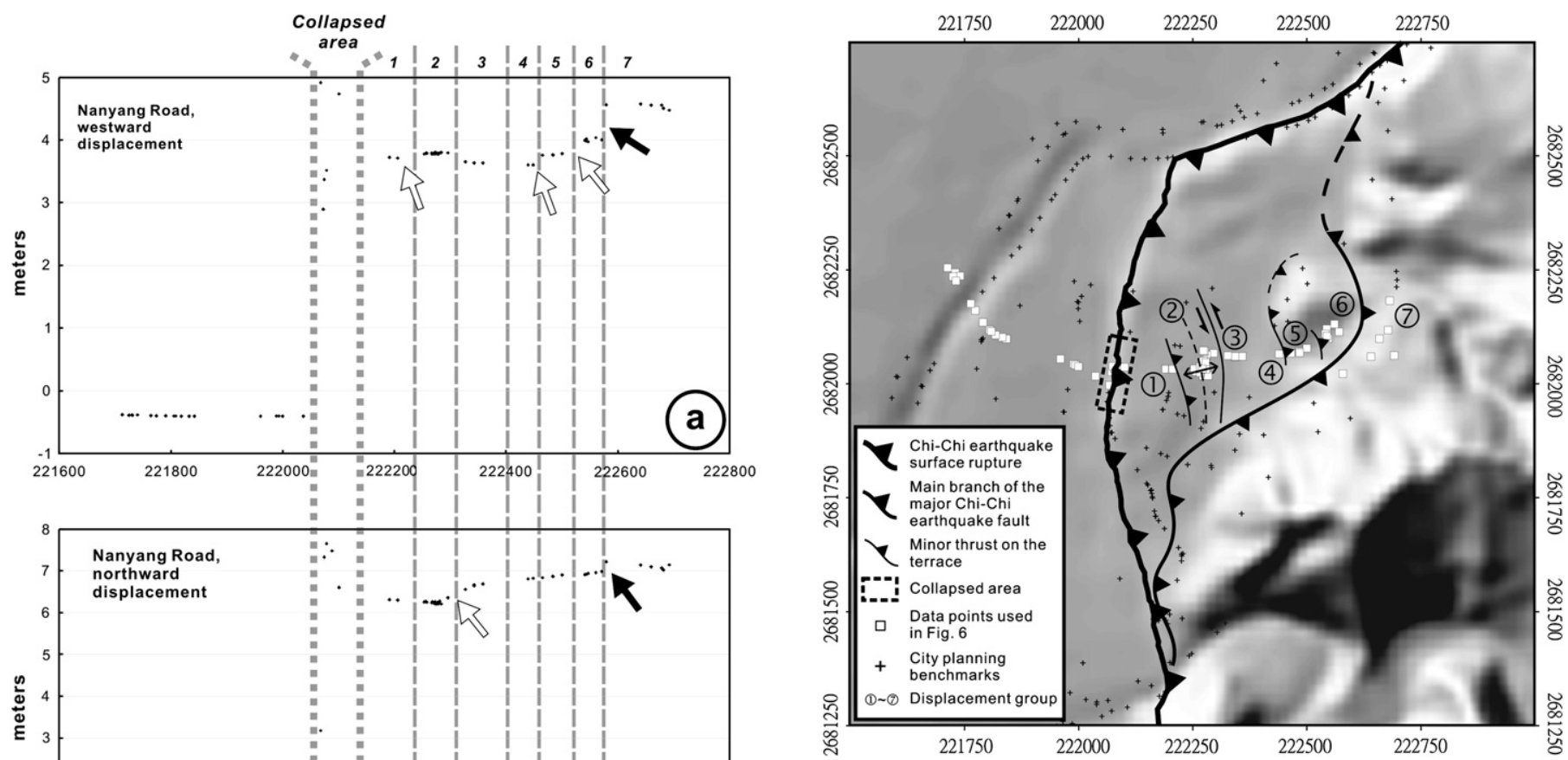

Fig. 7. Structural map of the southern Fengyuan study area. The thick line shows the main branch of the major Chi-Chi earthquake fault. Thin lines refer to minor structures in the terrace (strike-slip fault with a couple of arrows, pop-up structure with dashed line for axis, and divergent arrow indicating anticline type). Faults are shown as solid lines where observed and dashed lines where inferred. Circled numbers match groups of displacement differences in Fig. 6 .

Fig. 6. Displacement data of the Nanyang Road profile, with horizontal distance ( $x$ axis) and horizontal displacement component ( $y$-axis) in meters. (a) Westward displacement component. (b) Northward displacement component. Several groups of displacement data, referred to as $1-7$, are separated by grey dashed lines. Thick greydotted lines indicate bounds of the collapsed area along the major thrust rupture trace. Black arrows indicate the position of the active fault inside the hanging wall of the major thrust. White arrows refer to the locations of minor fault structures as mapped in Fig. 7.

deformation was expressed by minor faults and a pop-up structure. This example of distributed deformation (Figs. 6 and 7) provides evidence that co-seismic relative deformation was accommodated by two faults with several minor structures in between. If one of these faults and minor features been neglected, the total displacement across the Chelungpu Fault zone would have been underestimated by about $4.4 \mathrm{~m}$ instead of $7.3 \mathrm{~m}$ for the horizontal, SE-NW component, which is an underestimate of $40 \%$.

\section{Displacement amplitude map for hanging wall}

Considering the entire study area, the largest values of northward displacement (red and orange, Fig. 8a) appear in the northernmost area where displacement is essentially accommodated by a single fault. The southern terrace has smaller displacements with greater variation, reflecting the presence of the two faults with minor structures (Figs. 6 and 7). Interestingly, the greatest northward displacement occurred along the eastern fault (yellow color in Fig. 8a and b), with a left-lateral component increasing southward (Fig. 8a) and a reverse component increasing northward (Fig. 8b).

The large westward displacement values along the secondary thrust between the terrace and the hill (yellow-orange, Fig. 8b) highlight the importance of local co-seismic deformation. Consequently, the main fault that bounds the terrace to the west shows less displacement in the south (blue, Fig. 8a and b), as compared with the central and northern areas. Along this western edge of the

terrace, two small patches of large displacement are present (Fig. $8 a$ and $b$ ), however, they reflect local collapse near the primary fault scarp, rather than the true fault displacement.

The map of vertical displacement (Fig. 8c) reveals that in the northern area, strong co-seismic uplift occurred in the hanging wall along the rupture trace (yellow and orange, Fig. 8c). In this area, strong uplift also involved a NNW-SSE trending pop-up (orange and red, Fig. 8c) bounded by a backthrust (purple lines, Fig. 8c). In the southern area, strong uplift also occurred in the hanging wall along the primary rupture trace (yellow and red, Fig. 8c). Unfortunately, the absence of the vertical displacement data precluded mapping farther south along the western fringe of the terrace.

Not surprisingly, the footwall and back domain of the hanging wall front in the northern area show the least uplift/subsidence. In the southern area, the distribution of vertical movement clearly shows that the terrace was tilted towards the east, with a W-E transition from orange-red values to lesser green-blue ones. In more detail, local variations exist (yellow-orange patches) in the eastern terrace, which is consistent with the known minor structures (Figs. 6a and 7).

\section{Fault structure at shallow depths: a 3D fault geometry model}

The analysis of the co-seismic horizontal displacement shows that near the surface, the Chelungpu Fault splits into several branches, especially southeast of Fengyuan City. We combined the horizontal and vertical displacement data to evaluate the co-seismic slip in 3D, and hence, determine the dip angle and the fault at the shallow level. We assumed that the motion of the hanging wall is mainly controlled by fault geometry and that elastic deformation can be regarded as negligible. Consequently, the displacement of the hanging wall with respect to the footwall reflects directly the 


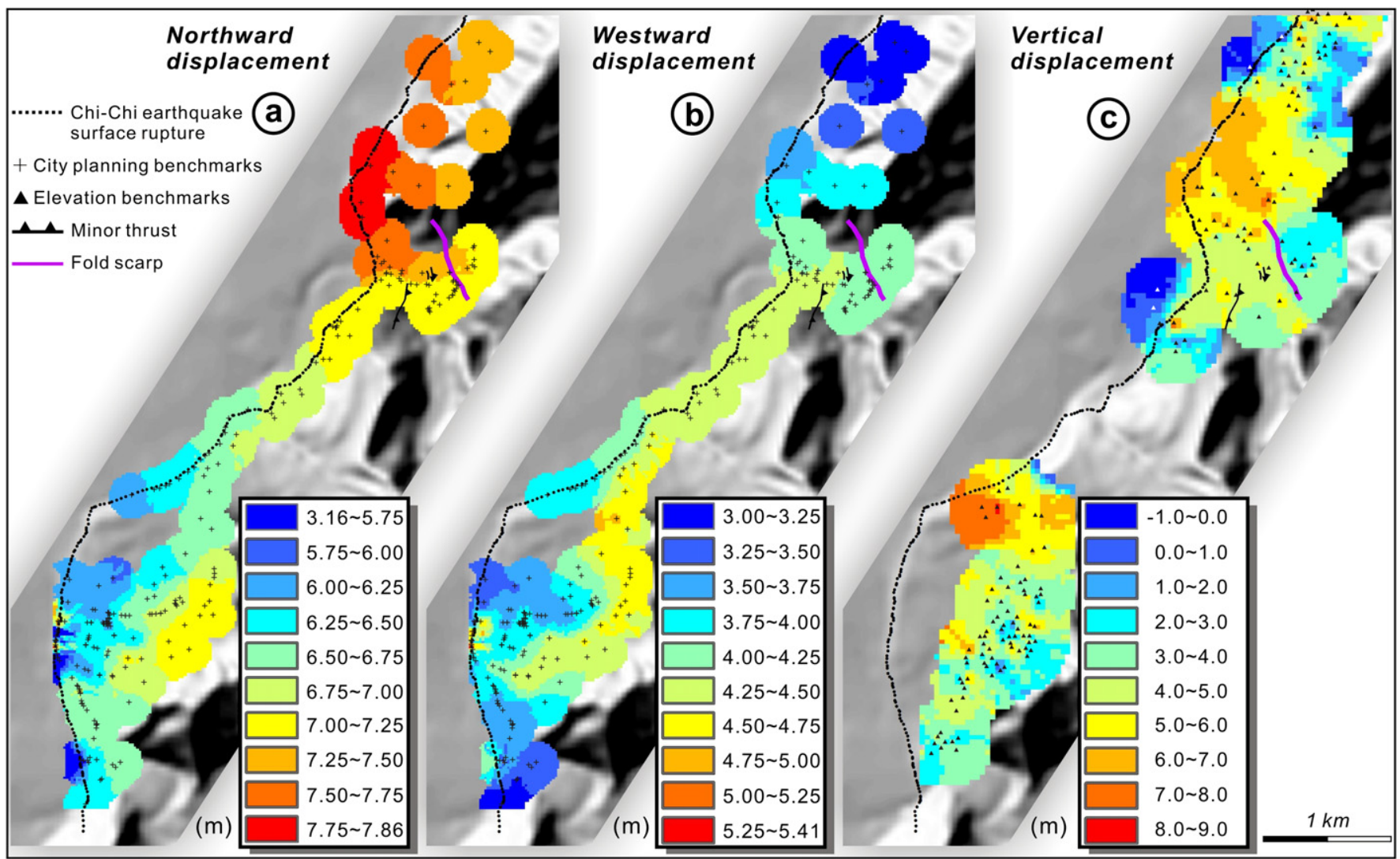

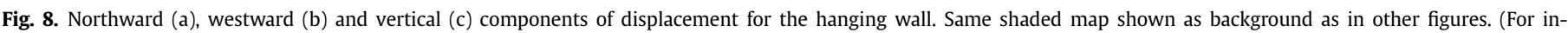
terpretation of the references to color in this figure legend, the reader is referred to the web version of this article.)

fault geometry, which allows reconstruction of a 3D fault geometry at shallow depths.

Because the horizontal and vertical displacements were commonly measured at separate benchmarks, we often used couples of neighbouring benchmarks for the horizontal and vertical displacement to constrain slip angle. We paired 62 city-planning benchmarks providing horizontal displacement with nearby benchmarks providing elevation data. We also simplified the fault trace in eastern Fengyuan City with seven rectangular data patches for 3D analysis (three patches in the north area, four in the south area, Fig. 9a).

We assume a local fault strike, calculate the slip-vector orientation from the appropriate benchmarks, combine the two lines to form a local fault plane, and then determine the fault depth based on a smooth curving fault surface passing through these local fault planes and the fault rupture on the surface (see Fig. 9d and e). We then constructed 44 cross-sections (Fig. 9b) perpendicular to fault strike and re-sampled the data points to calculate the variation in fault depth along each profile. Because each series of depth values was calculated with respect to the point where the profile meets the fault rupture at the surface, we adjusted the initial value to the elevation of the rupture trace after Chi-Chi earthquake. We also used the published measurements (Central Geological Survey, 1999; Lee et al., 2006) close to the fault scarp to calculate the fault dip near the surface rupture zone. Through data interpolation we constructed the contour map of the fault plane (Figs. 9e and 10).

The proposed surface of the Chelungpu Fault has a complex shape at shallow depths in the Fengyuan City area, with two prominent re-entrants in the footwall either side of a wide asymmetrical salient. In this salient, the dip of the earthquake fault became gentler at depth. A TCDP pilot-hole (Taiwan Chelungpu-Fault
Drilling Project, Ma et al., 2006) (Fengyuan well 2, Fig. 2) and an earlier exploratory drilling (Lee, 2001) (Fengyuan well 1, Fig. 2) met the fault. We compared our 3D model with the well data. Although the Fengyuan well 2 is located out of our benchmark coverage, the distance is small. Furthermore, according to shallow seismic observations and fault geometry models, fault shape at depth is smooth and parallel to the surface fault trace (Wang et al., 2002a; Yue et al., 2005).

In the Fengyuan well 2, the cored length was $315 \mathrm{~m}$ and the well data showed a shear zone (named N-MFZ-2) at a distance of $285.40-329.65 \mathrm{~m}$ along the inclined borehole from the surface (Tanaka et al., 2002). Most reports focused on the deeper shear zone in the well and used microstructure analysis or areal balancing method to demonstrate that the deeper shear zone was the 1999 Chi-Chi earthquake fault (Heermance et al., 2003; Lee et al., 2006). Within reasonable uncertainties the inferred position of the fault is very close to the well position, at about $250 \mathrm{~m}$ beneath the surface (Fig. 11). We consequently consider that the dip of the earthquake fault is well constrained here to about $50^{\circ}$ eastward. This local validation gives confidence to the prediction of fault shape farther to the north (Figs. 9 and 10). This good fit also suggests that our reasoning, which included the assumption of rigid displacement and displacement in the hanging wall dominated by fault geometry, was correct as a first approximation.

\section{Discussion of co-seismic movement in the hanging wall}

In the northern area (number 1, Fig. 2), the hanging wall is mainly composed of Chinshui Shale. The co-seismic displacement of the hanging wall unit in this area exhibits a clockwise rotation about benchmark \#1019 of about 7 min (Fig. 4a) in addition to the 

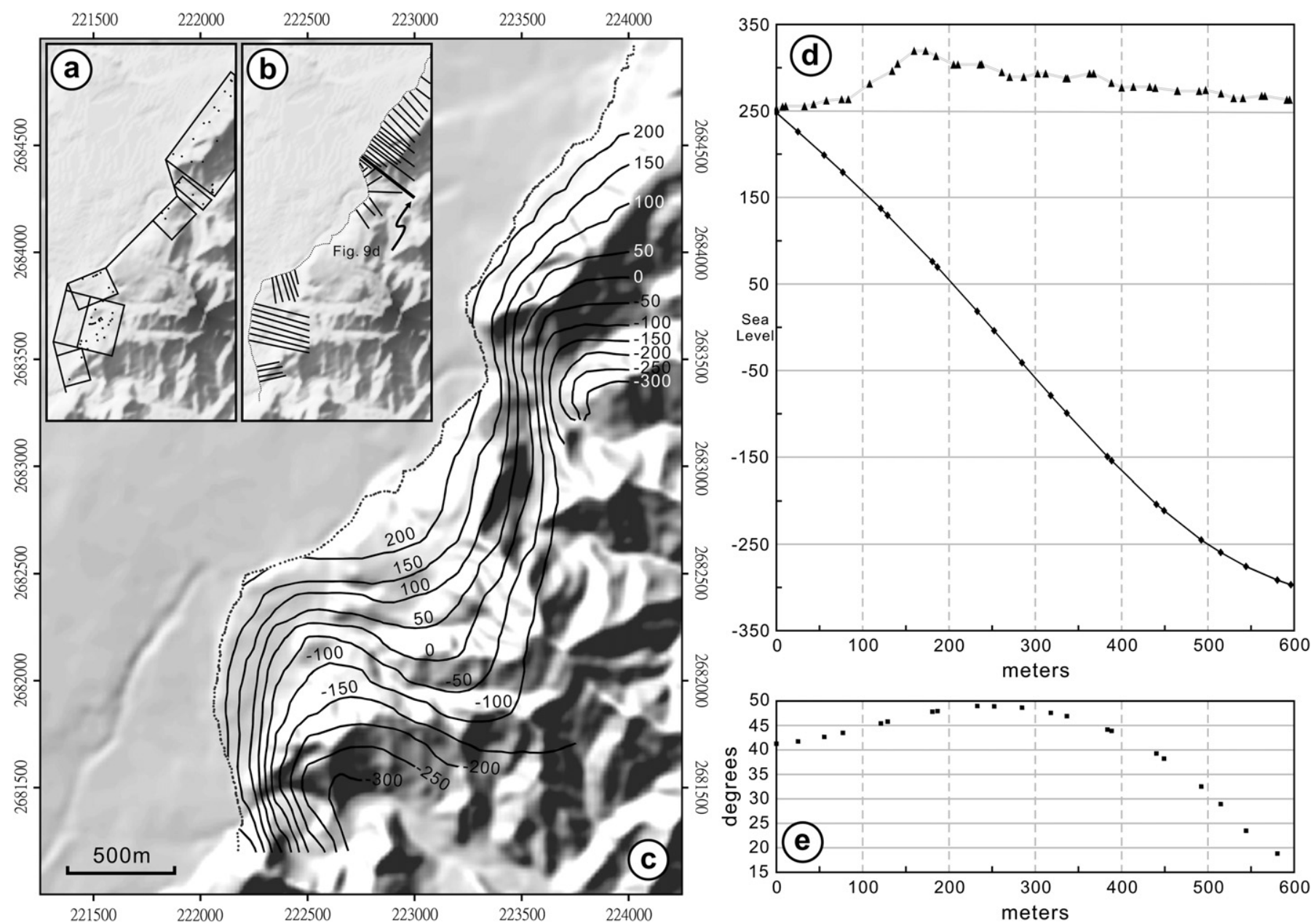

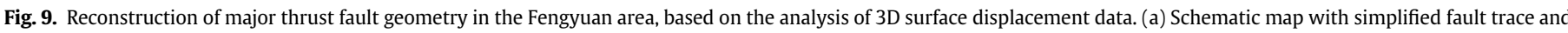

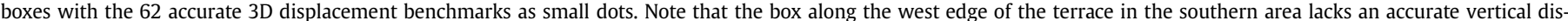

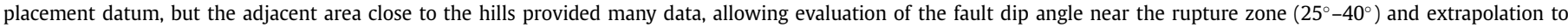

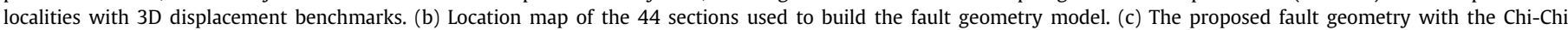

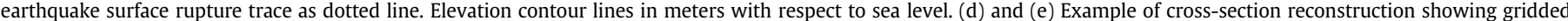

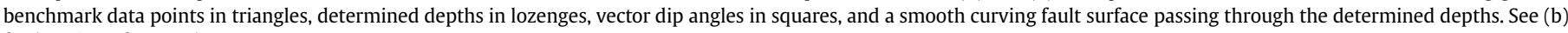
for location of example.

principal displacement to the northwest with respect to the footwall.

In the central study area (number 3, Fig. 2), the Hanhsi Creek valley is a transition zone between two salients in the thrust unit where the Chinshui Shale crops out (Fig. 2c). To the north (number 2, Fig. 2), the segment of the Hanhsi Creek may experience an E-W trending left-lateral shear to accommodate differential movement between the clockwise rotation of the northern area (Fig. 4a) and the translation of the thrust front in the central area (Fig. 4b). This hypothesis is consistent with the presence of multiple thrust and backthrust structures in the eastern Shueiyuan Road along the Hanhsi Creek.

In the southern area (number 4, Fig. 2), the structural pattern at shallow depths is more complex. The horizontal movement maps (Figs. 4b, 8a and b) reveal displacement discontinues between areas 3 and 4 , as well as the existence of two fault branches in area 4 . We suggest the boundary between areas 3 and 4 is a branch of the Chi-Chi earthquake fault because of about $1 \mathrm{~m}$ horizontal offset during the earthquake. A lateritic terrace is present, at an elevation of 50-75 m relative to the footwall in the northern part of area 4, unconformably overlying the Chinshui Shale. According to Ota et al. (2004), this terrace has no obvious warping and the flat surface indicates that no offset was caused by active structure within the terrace and that allows this terrace to have been homogeneously uplifted. Our analysis of the cityplanning benchmarks in Fengyuan City, however, indicates that significant, albeit minor co-seismic movements have occurred during the Chi-Chi earthquakes along several structural features within this terrace. The eastern lineament is the suspect active fault of Ota et al. (2004). Our study demonstrates that significant co-seismic movement indeed occurred along this lineament, which consequently deserves consideration as an active fault. The vector divergence with respect to hanging wall between areas 1 (north) and 4 (south), which brings independent kinematic support to our 3D reconstruction of the thrust fault at shallow depths, with a footwall salient (area 3 ) between two re-entrants (areas 1 and 4, Figs. 9 and 10). We further think that this geometric and kinematic pattern might indicate the presence of a lateral ramp underneath the western portion of area 3 . The north end of this ramp would lie beneath the Shueiyuan Road. This ramp would affect the hanging wall deformation, producing internal tensional stress in the terrace during the earthquake. Note also that maximum co-seismic uplift has occurred in the vicinity of the lateritic terrace (compare Fig. 8c and Fig. 2c).

Farther south and to the west, most of the area 4 is composed of a fluvial deposit terrace at the surface (Fig. 2c). This terrace is 


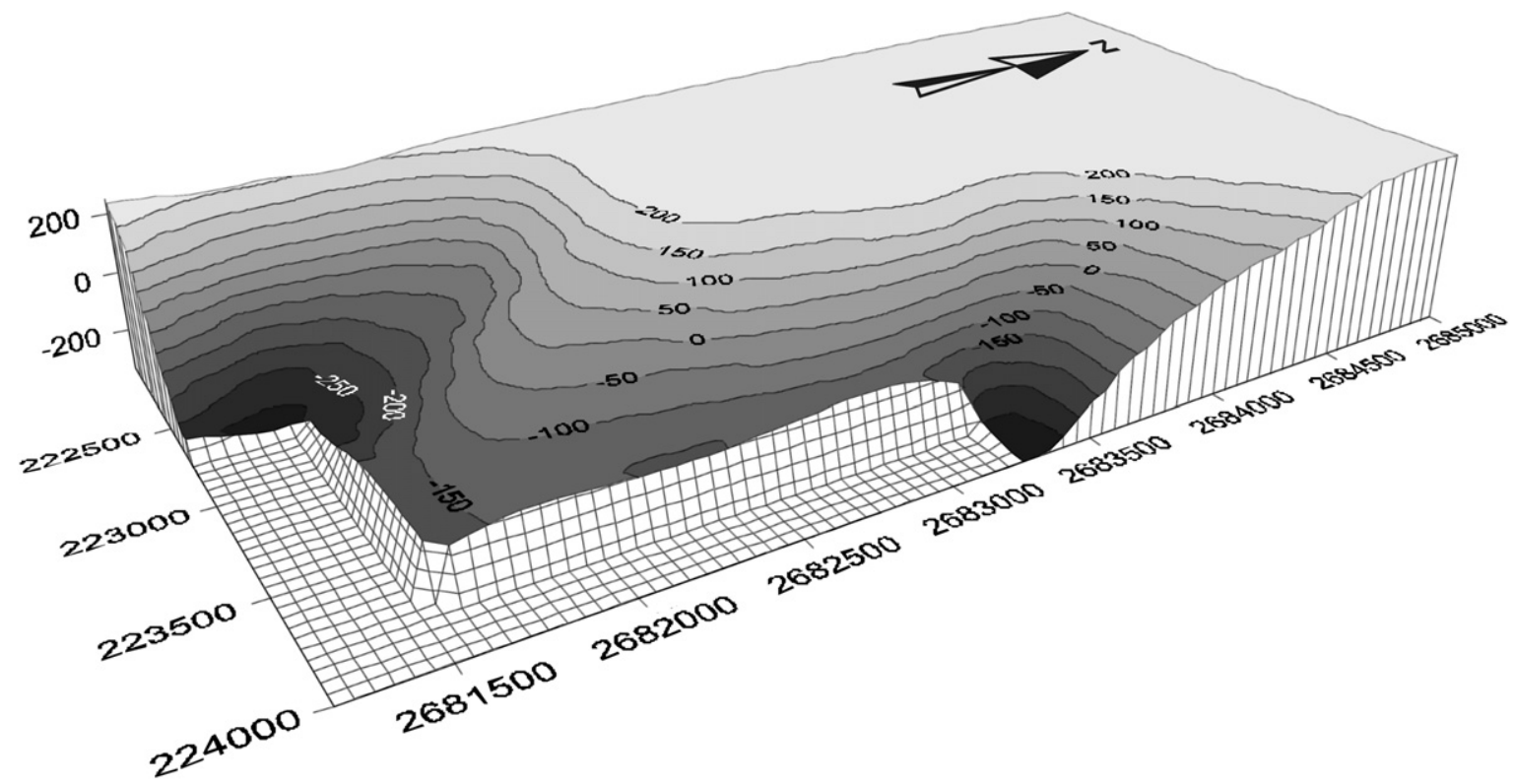

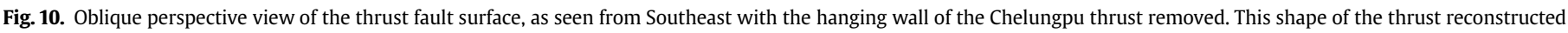
at depth is more sinuous than the surface trace.

mainly composed of sand, boulders and pebbles, without any lateritic character (Sino Geotechnology, Inc., 2002). As shown before, the boundary between this terrace and the hill area is a secondary earthquake fault with a co-seismic vertical offset of about $1 \mathrm{~m}$. The west boundary of this area is the main Chi-Chi earthquake fault, with 3-4 $\mathrm{m}$ of vertical uplift (Lee et al., 2006) and 5-8 $\mathrm{m}$ of horizontal displacement. Our model indicates that the fault dip is $25^{\circ}-$ $40^{\circ}$ here, much gentler than that to the north. The benchmarks on this terrace revealed a different displacement pattern as compared with other areas. The correlation of horizontal displacements and movement discontinuities revealed that inside the terrace the structural trends are mainly parallel to the topographic grain. In the middle of the terrace, we thus mapped a co-seismic anticline or pop-up like structure. Because the thickness of the fluvial deposits is $5-10 \mathrm{~m}$, and the bedrock underneath is mainly composed of shale to fine grained sandstone, the recorded motion of the benchmarks on the terrace reflect the mechanical properties of this thick unconsolidated material.

We interpret the southern terrace area is experiencing compression by the thrust unit composed of Chinshui Shale to the east, with a horizontal displacement of the shale of about $1 \mathrm{~m}$ westward relative to the terrace and a distribution of shortening accommodated by minor deformation within the 500 -m-wide terrace. Because the small co-seismic anticline is located in vacant land, we could not observe any building damage related to its formation. It is likely that this structure reflects the deformation at the top of the Chinshui Shale underlying the terrace. From the geo-electric survey data (Sino Geotechnology, Inc., 2002), we recognized the irregular shape at the top of the shale, which is consistent with the ramp of this gentle anticline being located on the unconformity above the Chinshui Shale. The other structures on the terrace are interpreted as accommodating co-seismic compression within the
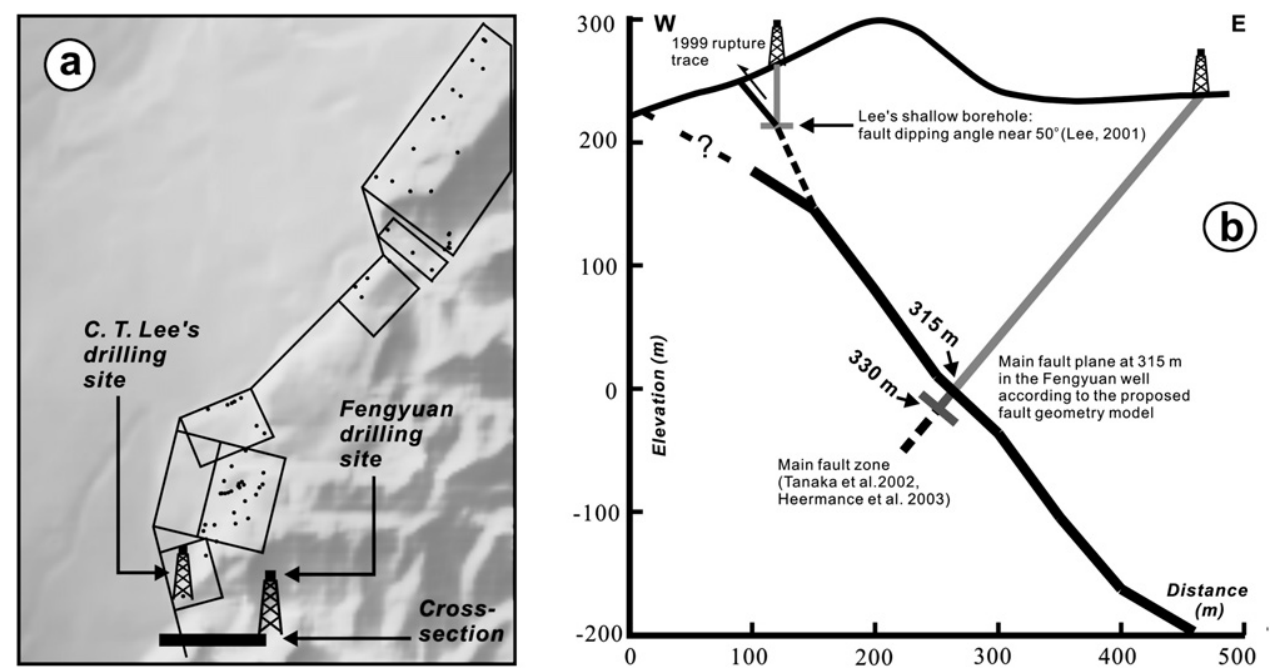

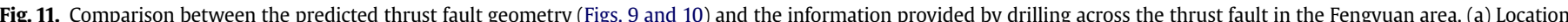

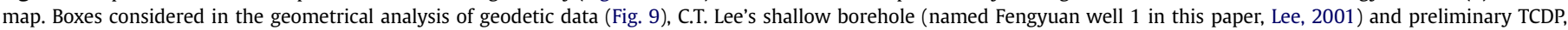

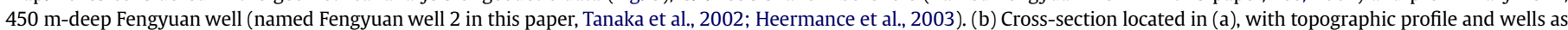

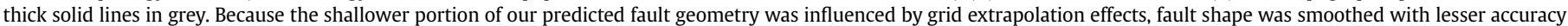
(dashed black line). 
unconsolidated Quaternary fluvial deposit. To summarise, the southern terrace area is characterized by co-seismic deformation mainly absorbed by two thrust faults near the edges of the terrace, with minor deformation inside the terrace. The front thrust fault has a significant change in trend as it runs $\mathrm{N}-\mathrm{S}$ along the western edge of the terrace and abruptly turns into the $\mathrm{N} 50^{\circ} \mathrm{E}$ direction to the north (Fig. 2). This particular pattern is again consistent with the hypothesis of a lateral ramp coming to the surface there, as suggested by our structural reconstruction (Figs. 9 and 10).

\section{Acknowledgements}

This work is supported by the Taiwan Earthquake Research Center (TEC) funded through National Science Council with grant No. NSC95-2745-M001-004 to Y.-C. Chan. The TEC contribution number for this article is 00032 . This work also benefited from the bilateral scientific collaboration under the framework of the L.I.A. France/Taiwan. We thank Alan Morris and Enrico Tavarnelli for their helpful and constructive reviews. We particularly thank Bill Dunne for his detailed scientific suggestions and English corrections, which have greatly improved the paper.

\section{References}

Angelier, J., 2002. Inversion of earthquake focal mechanisms to obtain the seismotectonic stress IV - a new method free of choice among nodal planes. Geophysics Journal International 150 (3), 588-609.

Angelier, J., Lee, J.C., Hu, J.C., Chu, H.T., 2003a. Reconstruction of fault slip of the September 21st, 1999, Taiwan earthquake in the asphalted surface of a car park, and co-seismic slip partitioning. Journal of Structural Geology 25, 351-370.

Angelier, J., Lee, J.C., Chu, H.-T., Hu, J.-C., Lu, C.-Y., Chan, Y.-C., Lin, T.-J., Font, Y., Deffontaines, B., Tsai, Y.-B, 2001. The Chichi earthquake, 1999, and its role in the Taiwan orogen. Comptes Rendus de l'Académie des Sciences - Series IIA: Earth and Planetary Science 333 (1), 5-21.

Angelier, J., Lee, J.C., Hu, J.C., Chu, H.T., 2003b. Three-dimensional deformation along the rupture trace of the September 21st, 1999, Taiwan earthquake: a case study in the Kungfu school. Journal of Structural Geology 25, 351-370.

Central Geological Survey, 1999. Report on the Geological Survey of the 1999 ChiChi Earthquake. Central Geological Survey, Ministry of Economic Affairs, Republic of China (Taiwan), 315 pp. (in Chinese).

Chan, Y.C., Okamoto, K., Yui, T.F., Iizuka, Y., Chu, H.T., 2005. Fossil fluid reservoir beneath a duplex fault structure within the Central Range of Taiwan: implication for fluid leakage and lubrication during earthquake rupturing process. Terra Nova 17, 493-499.

Chang, C.P., Chang, T.Y., Angelier, J., Kao, H., Lee, J.C., Yu, S.B., 2003. Strain and stress field in Taiwan oblique convergent system: constraints from GPS observation and tectonic data. Earth and Planetary Science Letters 214, 115-127.

Chinese Petroleum Corporation, 1974. Geological Map of Maio-Li. Scale 1/100,000. Chinese Petroleum Corporation, Republic of China (Taiwan).

Chen, W.S., Chen, Y.G., Shih, R.C., Liu, T.K., Huang, N.W., Lin, C.C., Sung, S.H., Lee, K.J. 2003. Thrust-related river terrace development in relation to the 1999 Chi-Chi earthquake rupture, Western Foothills, central Taiwan. Journal of Asian Earth Sciences 21, 473-480.

Dominguez, S., Avouac, J.P., Michel, R., 2003. Horizontal co-seismic deformation of the 1999 Chi-Chi earthquake measured from SPOT satellite images: implications for the seismic cycle along the western foothills of central Taiwan. Journal of Geophysical Research 108 (B2), 2083.

Dong, J.J., Wang, C.D., Lee, C.T., Liao, J.J., Pan, Y.W., 2003. The influence of surface ruptures on building damage in the 1999 Chi-Chi earthquake: a case study in Fengyuan City. Engineering Geology 71, 157-179.

Heermance, R., Shipton, Z.K., Evans, J.P., 2003. Fault structure control on fault slip and ground motion during the 1999 rupture of the Chelungpu Fault, Taiwan. Bulletin of the Seismological Society of America 93, 1034-1050.

Ho, C.S., 1986. A synthesis of the geologic evolution of Taiwan. Tectonophysics 125 $1-16$.

Hu, J.C., Angelier, J., Lee, J.C., Chu, H.T., Byrne, D., 1996. Kinematics of convergence, deformation and stress distribution in the Taiwan collision area: 2D finite-element numerical modelling. Tectonophysics 255, 243-268.
Hu, J.C., Yu, S.B., Angelier, J., Chu, H.T., 2001. Active deformation of Taiwan from GPS measurements and numerical simulations. Journal of Geophysical Research 106, 2265-2280.

Kao, H., Angelier, J., 2001. Stress tensor inversion for the Chi-Chi earthquake sequence and its implications on regional collision. Bulletin of the Seismological Society of America 91 (5), 1028-1040.

Kao, H., Chen, W.P., 2000. The Chi-Chi earthquake sequence: active, out-of-sequence thrust faulting in Taiwan. Science 288 (5475), 2346-2349.

Kao, H., Chen, R.Y., Chang, C.H., 2000. Exactly where does the 1999 Chi-Chi earthquake in Taiwan nucleate? Hypocenter relocation using the master station method. Terrestrial, Atmospheric and Oceanic Sciences 11, 567-580.

Kelson, K.I., Kang, K.H., Page, W.D., Lee, C.T., Cluff, L.S., 2001. Representative styles of deformation along the Chelungpu Fault from the 1999 Chi-Chi (Taiwan) earthquake: geomorphic characteristic and responses of man-made structures. Bulletin of the Seismological Society of America 91 (5), 930-952.

Lee, C.T., 2001. Technical Report of Shallow Drilling Project for the Chelungpu Fault National Central University, 44 pp. (in Chinese).

Lee, J.C., Chan, Y.C., 2007. Structure of the 1999 Chi-Chi earthquake rupture and interaction of thrust faults in the active fold belt of western Taiwan. Journal of Asian Earth Sciences 31, 226-239.

Lee, J.C., Chu, H.T., Angelier, J., Chan, Y.C., Hu, J.C., Lu, C.Y., Rau, R.J., 2002. Geometry and structure of northern surface ruptures of the $1999 \mathrm{Mw}=7.6$ Chi-Chi Taiwan earthquake: influence from inherited fold belt structures. Journal of Structural Geology 24, 173-192.

Lee, Y.H., Hsieh, M.L., Lu, S.D., Shih, T.S., Wu, W.Y., Sugiyama, Y., Azuma, T., Kariya, Y., 2003. Slip vectors of the surface rupture of the 1999 Chi-Chi earthquake, western Taiwan. Journal of Structural Geology 25, 1917-1931.

Lee, Y.H., Lu, S.D., Shih, T.S., 2006. Area balancing method as a useful tool to estimate the depth of the Chi-Chi earthquake rupture at the Fengyuan well. Terrestrial, Atmospheric and Oceanic Sciences 17, 489-502.

Lin, A., Ouchi, T., Chen, A., Maruyama, T., 2001. Co-seismic displacements, folding and shortening structures along the Chelungpu surface rupture zone occurred during the 1999 Chi-Chi (Taiwan) earthquake. Tectonophysics 330, 225-244.

Lin, C.W., Lee, Y.L., Huang, M.L., Lai, W.C., Yuan, B.D., Huang, C.Y., 2003. Characteristics of surface ruptures associated with the Chi-Chi earthquake of September 21, 1999. Engineering Geology 71, 13-30.

Ma, K.F., Tanaka, H., Song, S.S., Wang, C.Y., Hung, J.H., Tsai, Y.B., Mori, J., Song, Y.F, Yeh, E.C., Soh, W., Sone, H., Kuo, L.W., Wu, H.Y., 2006. Slip zone and energetics of a large earthquake from the Taiwan Chelungpu-fault Drilling Project. Nature 444 (23), 473-476.

Ministry of the Interior, 2001. Regulations of Measuring and Managing Urban Planning Benchmarks. Ministry of the Interior, Republic of China (Taiwan), 9 pp. (in Chinese).

Mouthereau, F., Angelier, J., Lee, J.-C., 2001. The 21-September-1999 earthquake: structural inheritance and basement involvement at the front of the Taiwan mountain. Comptes Rendus de l'Académie des Sciences - Series IIA: Earth and Planetary Science 333 (1), 93-103.

Ota, Y., Watanabe, M., Suzuki, Y., Sawa, H., 2004. Geomorphological identification of pre-existing active Chelungpu Fault in central Taiwan, especially its relation to the location of the surface rupture by the 1999 Chichi earthquake. Quaternary International 115-116, 155-166.

Philip, H., Meghraoui, M., 1983. Structural analysis and interpretation of the surface deformations of the El Asnam earthquake of October 10, 1980. Tectonics 2, 1749.

Seno, T., Stein, S., Gripp, A., 1993. A model for the motion of the Philippine Sea plate consistent with NUVEL-1 and geological data. Journal of Geophysical Research 98, 17941-17948.

Sino Geotechnology, Inc., 2002. Report on the Geological Survey of the Fu-Yang Elementary School, Taichung County, 127 pp. (in Chinese)

Tanaka, H., Wang, C.Y., Chen, W.M., Sakaguchi, A., Ujiie, K., Ito, H., Ando, M., 2002 Initial science report of shallow drilling penetrating into the Chelungpu Fault zone, Taiwan. Terrestrial, Atmospheric and Oceanic Sciences 13, 227-251.

Wang, C.Y., Li, C.L., Su, F.C., Leu, M.T., Wu, M.S., Lai, S.H., Chern, C.C., 2002a. Structura mapping of the 1999 Chi-Chi earthquake fault, Taiwan by seismic reflection methods. Terrestrial, Atmospheric and Oceanic Sciences 13, 211-226.

Wang, C.Y., Li, C.L., Yen, H.Y., 2002b. Mapping the northern portion of the Chelungpu Fault, Taiwan, by shallow reflection seismics. Geophysical Research Letters 29, 951-954.

Yu, S.B., Chen, H.Y., Kuo, L.C., 1997. Velocity field of GPS stations in the Taiwan area. Tectonophysics 274, 41-59.

Yu, S.B., Kuo, L.C., Hsu, Y.J., Su, H.H., Liu, C.C., Hou, C.S., Lee, J.F., Lai, T.C., Liu, C.C., Liu, C.L., Tseng, T.F., Tsai, C.S., Shin, T.C., 2001. Preseismic deformation and coseismic displacements associated with the 1999 Chi-Chi, Taiwan earthquake. Bulletin of the Seismological Society of America 91 (5), 995-1012.

Yue, L.F., Suppe, J., Hong, J.H., 2005. Structural geology of a classic thrust belt earthquake: the 1999 Chi-Chi earthquake Taiwan $(\mathrm{Mw}=7.6)$. Journal of Structural Geology 27, 2058-2083. 